\title{
Effect of lidocaine infusion compared to dexmedetomidine infusion on proinflammatory cytokines and stress response in pelvi-abdominal cancer surgeries: a randomized clinical trial
}

\author{
Mohamed Mahmoud Hassan ${ }^{1} \bowtie$, Emad Gerges Saleh ${ }^{2} \bowtie$, Norma Osama Abdalla ${ }^{3}$, \\ Noha Hassan Radwan ${ }^{4} \bowtie$, Ekramy Mansour Abdelghfar ${ }^{1} \bowtie$
}

Author affiliation:

1. Lecturer, Department of Anesthesiology, Surgical ICU and Pain Management, National Cancer Institute, Cairo University, Cairo, Egypt.

2. Professor, Department of Anesthesiology, Surgical ICU and Pain Management, National Cancer Institute, Cairo University, Cairo, Egypt.

3. Assistant Lecturer, Department of Anesthesiology, Surgical ICU and Pain Management, National Cancer Institute, Cairo University, Cairo, Egypt.

4. Lecturer, Department of Clinical Pathology and Oncological Laboratory Medicine, National Cancer Institute, Cairo, Egypt.

5. Assistant Professor, Department of Anesthesia, Surgical ICU and Pain Medicine, National Cancer Institute, Cairo, Egypt.

Correspondence: Norma Osama Abdalla; E-mail: normazayed@yahoo.com; Phone: 00201067843111

\section{Abstract}

Background \& Objectives: Stress response to extensive surgeries in cancer patients results in an imbalance between the pro-inflammatory and anti-inflammatory cytokines, besides activating an inflammatory cascade. We investigated the comparative effects of intravenous infusion of dexmedetomidine and lidocaine on proinflammatory cytokines and the stress reaction.

Methodology: A prospective randomized double blind trial was performed in National Cancer Institute. 54 patients scheduled for pelvi-abdominal cancer surgery under general anesthesia were randomly allocated to three equal groups. Lidocaine group: patients received $1.5 \mathrm{mg} / \mathrm{kg}$ loading dose of lidocaine followed by $1.5 \mathrm{mg} / \mathrm{kg} / \mathrm{h}$ infusion; Dexmedetomidine group: received a loading dose of dexmedetomidine $1 \mu \mathrm{g} / \mathrm{kg}$ followed by infusion of $0.5 \mu \mathrm{g} / \mathrm{kg} / \mathrm{h}$; or Saline group: received $50 \mathrm{ml}$ of normal saline followed by infusion at a rate of $10 \mathrm{ml} / \mathrm{h}$ till the end of the surgery. The primary outcome was a postoperative target level of IL-6 after $24 \mathrm{~h}$.

Results: Immediate and $24 \mathrm{~h}$ postoperative IL-6 and TNF $\alpha$ were significantly lower in both dexmedetomidine and lidocaine groups compared to the control group $(\mathrm{P}<0.001)$. Dexmedetomidine group had a significantly lower IL 6 and TNF $\alpha$ levels compared to lidocaine group at immediate postoperative and $24 \mathrm{~h}$ postoperative period $(\mathrm{P}<0.001)$. Dexmedetomidine and lidocaine groups had a significantly lower lactate and insulin levels compared to the control group immediately postoperatively as well as $24 \mathrm{~h}$ postoperatively $(\mathrm{P}<0.001)$. The dexmedetomidine group had a significantly lower lactate levels compared to the lidocaine group immediately postoperatively only. The lidocaine group had lower insulin level than the control group regarding immediate postoperative period only.

Conclusion: Intraoperative infusion of dexmedetomidine or lidocaine, both attenuate the postoperative levels of proinflammatory cytokines and stress response in patients undergoing pelvi-abdominal cancer surgeries.

Clinical trial registration: The study was registered at clinicaltrials.gov (NCT 04148599).

Key words: Lidocaine; Dexmedetomidine; Interleukins; Tumor necrosis factor- $\alpha$; Stress response; Pelvi-abdominal cancer; Surgery

Abbreviations: TNF - Tumor necrosis factor; IL - Interleukins; 
Citation: Hassan MM, Saleh RG, Abdalla NO, Radwan NH, Abdelghfar EM. Effect of lidocaine infusion compared to dexmedetomidine infusion on proinflammatory cytokines and stress response in pelvi-abdominal cancer surgeries: a randomized clinical trial. Anaesth. pain intensive care 2021;26 (1):44-52. DOI: 10.35975/apic.v26i1.1765

Received: February 15, 2021, Reviewed: December 02, 2021, Accepted: December 05, 2021

\section{Introduction}

Stress response to cancer surgeries is usually associated with a group of interactions between the endocrinal, the sympathetic, and the immunological systems, resulting in imbalance between pro- and anti-inflammatory cytokines in addition to, activating an inflammatory cascade. $^{1,2}$

Exaggerated production of stress hormones (i.e. catecholamine, cortisol, and glucose), inflammatory mediators (e.g. interleukins [ILs] and tumor necrosis factor alpha $[\mathrm{TNF} \alpha]$ ), and immune cell dysfunction (e.g. CD4 T) can lead to hemodynamic instability or metabolic derangements besides increasing the susceptibility of postoperative infection, resulting in delaying wound healing, multiple organ dysfunction, and postoperative morbidity. ${ }^{3}$

Dexmedetomidine; is a highly selective alpha2 adrenoceptor agonist which induces sedation, analgesia and anxiolysis. The sympatholytic activity of dexmedetomidine can suppress the inflammatory and surgical stress response and preserve the immunity of surgical patients. Though, there are no existing reviews of literature which offer a strong conclusion of the role of dexmedetomidine on perioperative inflammatory or immunological stresses. , $^{2}$

The antinociceptive effects of lidocaine are due to sodium channels and potassium neuronal currents block, presynaptic muscarinic and dopaminergic receptors block. Clinical studies demonstrated the effect of intravenous (IV) lidocaine in abdominal surgeries resulting in reducing the postoperative pain scores and opioid consumption. ${ }^{6,7}$ However, there are few studies assessed the role of lidocaine in decreasing surgical stress response. ${ }^{8}$

Therefore, the current study was performed to assess the effect of dexmedetomidine IV infusion and lidocaine on proinflammatory cytokines (IL-6 and TNF $\alpha$ ) and some stress reactions (serum insulin and lactate).

\section{Methodology}

This prospective randomized controlled double-blind trial was conducted in the National Cancer Institute, Cairo University during December 2019 to June 2020 following the approval of the Institutional Review Board (Approval No.201617050.3). The study was registered at clinicaltrials.gov (NCT 04148599).
Fifty-four patients; includes both genders, their age ranges between 18 to 60, with a physical status of II-III American Society of Anesthesiology (ASA) and a BMI $<30 \mathrm{~kg} / \mathrm{m} 2$, scheduled for pelvi-abdominal cancer surgery, were enrolled in the current study after consent by all participants. Exclusion criteria included, known allergic history to the study drugs, myocardial ischemia within the previous six months, renal or liver function impairment, pregnancy, chronic opioid use, a history of chronic pain, the inability to provide written informed consent and patient refusal.

\subsection{Randomization}

Patients were randomly assigned to one of the three study groups on the surgery day. Grouping was determined through a computer-generated list that was kept in a sealed envelope. Both patients and anesthetists who participated in postoperative data collection, were blinded to the treatment group. All groups initially received general anesthesia and one of the three analgesic techniques was then conducted; Group D received an infusion of dexmedetomidine, Group L received infusion of lidocaine, while Group $\mathrm{C}$ received a saline infusion intraoperatively.

\subsection{Blinding}

An anesthesiologist, who was not involved in the anesthesia management, prepared the covered syringe pumps for the dexmedetomidine, lidocaine and saline, besides being responsible for the randomization codes till the end of the study. Another anesthesiologist, who was not involved in postoperative patient evaluation and was blinded to the group assignments, administered anesthesia. Patients and the anesthesiologist-in-charge were blinded to the group assignments throughout the whole period of study.

\subsection{Anesthetic management}

In the preoperative holding area, an IV access was secured and crystalloid infusion started. Patients were premedicated with midazolam $0.05 \mathrm{mg} / \mathrm{kg}$ IV and ondansetron $4 \mathrm{mg}$ IV. Standard monitoring, capnography and respiratory gas analysis were conducted.

Anesthesia was induced with Fentanyl $2 \mu \mathrm{g} / \mathrm{kg} \mathrm{IV}$, propofol $2 \mathrm{mg} / \mathrm{kg}$ and bolus of atracurium $0.5 \mathrm{mg} / \mathrm{kg}$. After tracheal intubation, anesthesia was maintained with sevoflurane; its concentration being adjusted to ensure adequate depth of anesthesia guided by the 


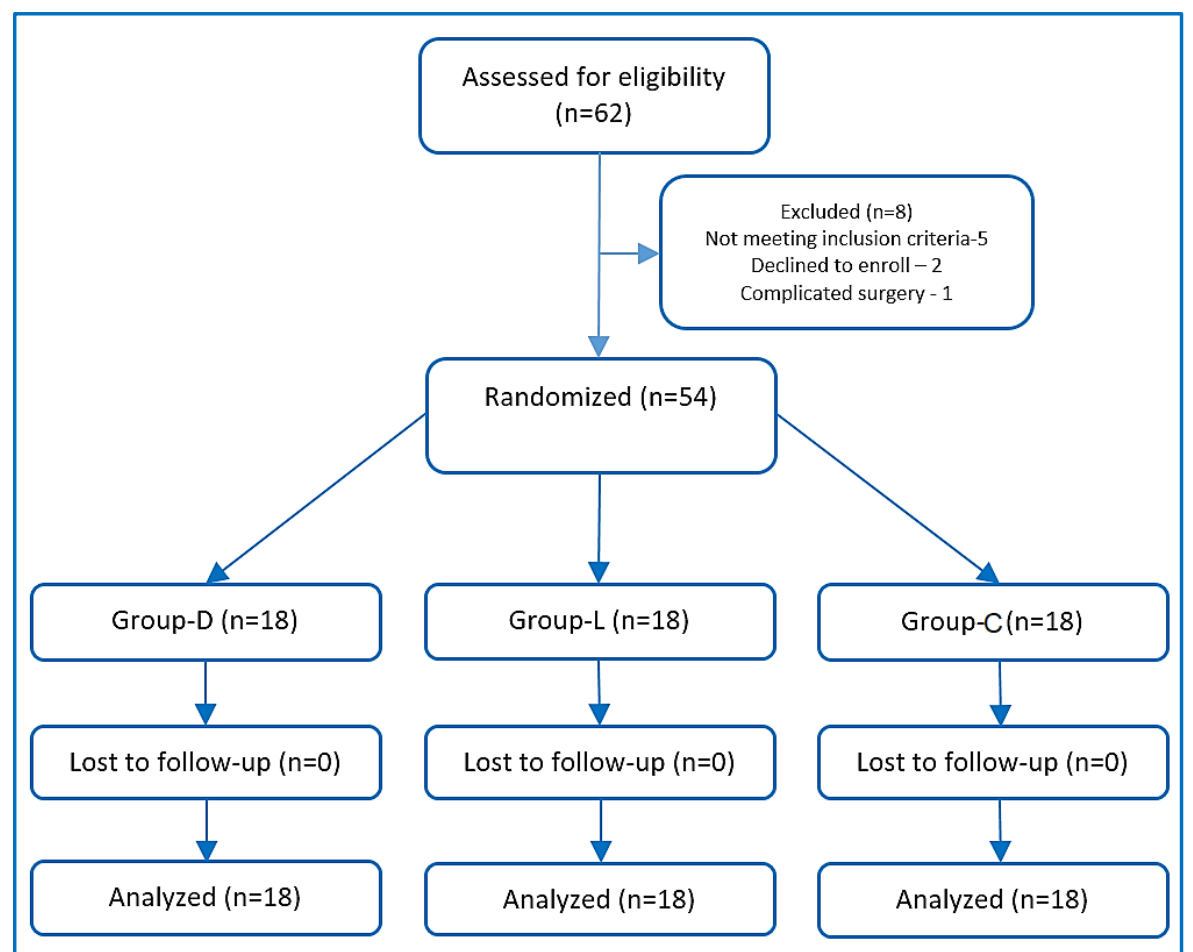

Figure 1: CONSORT flowchart of patients

maintenance of the bispectral index (BIS) at 45 to 60 . Patients were ventilated with volume control ventilation mode at tidal volumes of $6-8 \mathrm{ml} / \mathrm{kg}$ and at respiratory rates to maintain end-tidal carbon dioxide (EtCO2) concentration around $35 \mathrm{mmHg}$, and an inspired oxygen fraction $(\mathrm{FiO} 2)$ of 0.6 .

\subsection{Intervention}

Immediately after anesthesia induction, one of the three regimens was started; group L receiving $1.5 \mathrm{mg} / \mathrm{kg}$ loading dose of lidocaine, made to $50 \mathrm{ml}$ using normal saline given over $10 \mathrm{~min}$, and followed by infusion at 1.5 $\mathrm{mg} / \mathrm{kg} / \mathrm{h}$ till the end of surgery; Group D received a loading dose of $1 \mu \mathrm{g} / \mathrm{kg}$ of dexmedetomidine made to 50 $\mathrm{ml}$ using normal saline and given over $10 \mathrm{~min}$ followed by infusion at $0.5 \mu \mathrm{g} / \mathrm{kg} / \mathrm{h}$ till the end of surgery; and Group C received $50 \mathrm{ml}$ of normal saline given over 10 min followed by a saline infusion intraoperatively at a rate of $10 \mathrm{ml} / \mathrm{h}$ till the end of the surgery.

The infusions were stopped after skin closure. After the reversal of neuromuscular blocking agent and the response to verbal command, patients were extubated in the operating room. Subsequently, they were transferred to post anesthesia care unit (PACU).

The heart rate (HR) and mean arterial blood pressure (MAP) were recorded before infusion, every $15 \mathrm{~min}$ intraoperatively as well as postoperatively at $0,2,6,12$ and $24 \mathrm{~h}$.

Bradycardia was defined as a HR less than $50 \mathrm{BPM}$, and treated by $0.5 \mathrm{mg}$ of atropine. Hypotension was defined as a $20 \%$ decrease in the MAP from the baseline record, and was treated by increments of ephedrine $3 \mathrm{mg}$ IV.

Pain intensity was assessed, in PACU via the visual analogue scale (VAS) at 0, 2, 6, 12 and $24 \mathrm{~h}$. Paracetamol $1 \mathrm{gm}$ every $6 \mathrm{~h}$ were set as postoperative analgesia in all study groups. A rescue analgesia was given for VAS $\geq 4$ using an opioid (morphine $3 \mathrm{mg}$ ). Time of the first rescue analgesia together with the total dose of morphine were recorded.

The $24 \mathrm{~h}$ postoperative blood level of IL-6 was set as the primary outcome of this study. The following were set as secondary outcomes of the current study: (i) Immediate postoperative levels of IL-6, (ii) immediate postoperative and $24 \mathrm{~h}$ postoperative levels of TNF $\alpha$, and plasma levels of insulin and lactate; (iii) The average end tidal concentration of sevoflurane (recorded every $15 \mathrm{~min}$ ); (iv) First $24 \mathrm{~h}$ postoperative VAS, and (v) $24 \mathrm{~h}$ postoperative morphine consumption.

\subsection{Samples collection and analysis}

Blood samples were obtained $10 \mathrm{~min}$ before drug infusion, by the end of surgery, and $24 \mathrm{~h}$ after surgery, to measure plasma levels of IL $-6, \mathrm{TNF} \alpha$, and plasma levels of insulin and lactate.

$5 \mathrm{ml}$ of venous blood was withdrawn for each sample under complete aseptic precautions in a plain vacutainer tube. They were left to clot for $30 \mathrm{~min}$, centrifuged at $\mathrm{x} 3000 \mathrm{~g}$ for $10 \mathrm{~min}$, then the serum was separated in 4 aliquots; one for IL-6, one for TNF, one for insulin and one for lactate. Aliquots were stored at $-20 \circ \mathrm{C}$ till time of essay. Serum levels were assessed using sandwichELISA (enzyme linked immunosorbent assay) method by using Tecan- Sunrise device (Tecan Austria GmbH).

\subsection{Sample size estimation}

Based on a pilot study, in which each group consisted of ten patients, sample size was calculated according to the significant difference in the mean of $24 \mathrm{~h} \mathrm{IL}-6$ (as a primary outcome) among the control group (115.34 \pm 13.94), dexmedetomidine group $(38.05 \pm 9.50)$ and lidocaine group $(82.15 \pm 16.58)$ using ANOVA test, with $\alpha=0.05$, power of $80 \%$, and an effect size of 0.44 . The total sample size was 45 participants with 15 per group, was raised up to 54 participants (18 per group) to allow 
the use of a non-parametric test. Calculation of sample size was by $\mathrm{G}^{*}$ Power program (University of Düsseldorf, Düsseldorf, Germany).

\subsection{Statistical analysis}

Data were analyzed using IBM SPSS version 25 (SPSS Inc., Chicago, IL). Normally distributed numerical data are presented as mean $\pm \mathrm{SD}$ and between-group differences were compared using one-way analysis of variance (ANOVA), with a post-hoc Tukey test to detect significant difference among research groups. Abnormally distributed numerical data were presented as a median (IQR), and inter-group differences were compared using the Kruskal Wallis test, with post-hoc Mann-Whitney U-test to detect significant difference among research groups. Categorical data were presented as number of patients and percent, and they were compared using the Pearson $\chi 2$ test. A two-tailed $\mathrm{P}<$ 0.05 was considered significant.

\section{Results}

Sixty-two patients were screened for the current research; 5 patients were excluded, as they did not meet our inclusion criteria, two patients refused to participate, and one patient didn't replenish the procedures of the research due to surgical complication (vascular injury). 54 patients, 18 per each group, were included in the randomization process (Figure 1).

The patients demographic characteristics were compared in the three groups of the research as displayed in Table 1.

Preoperative HR, MAP, IL-6, TNF $\alpha$, serum lactate and insulin were insignificantly different among the three groups.

Regarding levels of IL-6 and TNF $\alpha$, there were significant differences between the three groups, in both immediate postoperative and $24 \mathrm{~h}$ postoperative samples $(\mathrm{P}<0.001)$. The dexmedetomidine group had a significantly lower IL-6 and TNF $\alpha$ levels compared to, both the control and lidocaine groups in immediate postoperative period. Also, lidocaine group had a significantly lower IL-6 and TNF $\alpha$ levels compared to the control group, immediate postoperatively and $24 \mathrm{~h}$ postoperatively (Table 2).

Similarly, there was a significant difference between the three groups regarding serum lactate, in immediate postoperative and $24 \mathrm{~h}$ postoperative samples $(\mathrm{P}<$ 0.001). Both of the dexmedetomidine and lidocaine groups had a significantly lower lactate levels compared to the control group, at immediately postoperative and 24 $\mathrm{h}$ postoperative readings. The dexmedetomidine group had significantly lower lactate levels compared to the lidocaine group, at immediately postoperative period only (Table 2).

Regarding the insulin level, the dexmedetomidine group had significantly lower levels of insulin, compared to the control immediately postoperatively, and $24 \mathrm{~h}$ postoperatively $(\mathrm{P}<0.001)$. The lidocaine group had lower insulin level than the control group, in the immediate postoperative period only (Table 2).

In regard to both the intraoperative MAP, and HR, the dexmedetomidine group showed lower values, compared to control groups throughout all of the intraoperative time points. The lidocaine group also had a lower MAP and HR when compared to the control group, showing a significant difference in all time points regarding $\mathrm{HR}$, while showing a significant difference at some of the time points regarding MAP (at 15, 30,75,105 and 120 min). The dexmedetomidine group also had a lower MAP and HR when compared to the lidocaine group showing a significant difference in all time points with reference to $\mathrm{HR}$, while showing only a significant difference at $90 \mathrm{~min}$ regarding the MAP. (Figure 2, Figure 3) Five patients in the dexmedetomidine group in addition to three patients in the lidocaine group, developed hypotension, which was treated by boluses ephedrine in all cases, the arterial blood pressure was normalized. None of the study patients developed bradycardia.

The dexmedetomidine had a significantly lower postoperative MAP as well as a lower HR, compared to the control group, at all time points. The lidocaine group

\begin{tabular}{|c|c|c|c|c|}
\hline Parameter & Group D & Group L & Group C & P-value \\
\hline Age (years) & $46.1 \pm 6.7$ & $44.5 \pm 5.32$ & $45.7 \pm 8.16$ & 0.773 \\
\hline Gender Male & $8(44.4)$ & $6(33.3)$ & $8(44.4)$ & 0.163 \\
\hline ASA & & & & 0.134 \\
\hline II & 7 (38.9) & 7 (38.9) & $10(55.6)$ & \\
\hline III & $11(61.1)$ & $11(61.1)$ & $8(44.4)$ & \\
\hline \multicolumn{5}{|c|}{$\begin{array}{l}\text { Data of age, Heart rate, IL-6, TNF } \alpha \text {, lactate and insulin are presented as mean } \pm S D \text {. Data of gender ana } \\
\text { ASA are presented as number (\%). } P>0.05 \text { is considered statistically nonsignificant. Group D: } \\
\text { dexmedetomidine group; Group L: lidocaine group; Group C: saline group. }\end{array}$} \\
\hline
\end{tabular}




\begin{tabular}{|c|c|c|c|c|}
\hline Sampling time & $\begin{array}{r}\text { Group D } \\
(n=18)\end{array}$ & $\begin{array}{c}\text { Group L } \\
(n=18)\end{array}$ & $\begin{array}{r}\text { Group C } \\
(n=18)\end{array}$ & P-value \\
\hline \multicolumn{5}{|l|}{ IL-6 levels (pg/ml) } \\
\hline Preoperative & $3.93 \pm 2.07$ & $3.67 \pm 2.09$ & $3.48 \pm 1.66$ & 0.79 \\
\hline Immediate postoperative & $19.3 \pm 7.56 \#$ & $55.75 \pm 13.3$ & $74.77 \pm 7.9$ \$o & $*<0.001$ \\
\hline $24 \mathrm{~h}$ postoperative & $37.3 \pm 9.51 \#$ & $80.5 \pm 13.52$ & $116.4 \pm 15.35$ \$o & $*<0.001$ \\
\hline \multicolumn{5}{|l|}{ TNFa (pg/ml) } \\
\hline Preoperative & $1.41 \pm 0.18$ & $1.4 \pm 0.17$ & $1.44 \pm 0.21$ & 0.755 \\
\hline Immediate postoperative & $3.2 \pm 0.33 \#$ & $5.92 \pm 0.9$ & $7.36 \pm 1.65 \$ 0$ & ${ }^{*}<0.001$ \\
\hline $24 \mathrm{~h}$ postoperative & $4.68 \pm 0.96 \#$ & $7.2 \pm 0.56$ & $8.7 \pm 1.05 \$ 0$ & $*<0.001$ \\
\hline \multicolumn{5}{|l|}{ Serum lactate $(\mathrm{ng} / \mathrm{ml})$} \\
\hline Preoperative & $3.93 \pm 0.18$ & $3.95 \pm 0.42$ & $3.86 \pm 0.43$ & 0.872 \\
\hline Immediate postoperative & $4.39 \pm 0.33 \#$ & $5.42 \pm 0.85$ & $7.14 \pm 1.35$ \$o & $*<0.001$ \\
\hline 24hrs postoperative & $3.88 \pm 0.96$ & $4.48 \pm 0.87$ & $6.44 \pm 2.03 \$ 0$ & $*<0.001$ \\
\hline \multicolumn{5}{|l|}{ Serum insulin (ng/ml) } \\
\hline Preoperative & $1.4 \pm 0.48$ & $1.69 \pm 0.47$ & $1.85 \pm 0.83$ & 0.082 \\
\hline Immediate postoperative & $1.62 \pm 0.5$ & $1.77 \pm 0.51$ & $2.66 \pm 0.96 \$ 0$ & $*<0.001$ \\
\hline $24 \mathrm{~h}$ postoperative & $1.59 \pm 0.52$ & $1.9 \pm 0.48$ & $2.15 \pm 0.63^{\circ}$ & $* 0.012$ \\
\hline \multicolumn{5}{|c|}{$\begin{array}{l}\text { Data presented as mean } \pm S D .{ }^{*} \text { denotes significance between the } 3 \text { groups, }{ }^{*} \text { denotes significance between } D \\
\text { and } L \text { groups, } \$ \text { denotes significance between } L \text { and } C \text { groups, } O \text { denotes significance between } D \text { and } C \text { groups.. } \\
p g / m l=\text { picogram per milliliter }=n g / m l: \text { nanogram per millilitre. }\end{array}$} \\
\hline
\end{tabular}

\begin{tabular}{|c|c|c|c|c|}
\hline Recording time & $\begin{array}{r}\text { Group D } \\
(n=18)\end{array}$ & $\begin{array}{c}\text { Group L } \\
(n=18)\end{array}$ & $\begin{array}{c}\text { Group C } \\
(n=18)\end{array}$ & P-value \\
\hline $15 \mathrm{~min}$ & $1.33 \pm 0.1$ & $0.12 \pm 1.61$ & $0.2 \$ 0 \pm 2.16$ & $*<0.001$ \\
\hline $30 \mathrm{~min}$ & $1.32 \pm 0.09$ & $1.65 \pm 0.125$ & $2.7 \pm 0.18 \$ 0$ & $*<0.001$ \\
\hline $45 \min$ & $1.32 \pm 0.06$ & $1.66 \pm 0.14$ & $2.15 \pm 0.2 \$ 0$ & $*<0.001$ \\
\hline $60 \mathrm{~min}$ & $1.3 \pm 0.076$ & $1.7 \pm 0.14$ & $2.18 \pm 0.19 \$ 0$ & ${ }^{*}<0.001$ \\
\hline $75 \mathrm{~min}$ & $1.3 \pm 0.1$ & $1.66 \pm 0.15$ & $2.18 \pm 0.21 \$ 0$ & ${ }^{*}<0.001$ \\
\hline $90 \mathrm{~min}$ & $1.28 \pm 0.1$ & $1.71 \pm 0.1$ & $2.21 \pm 0.17$ \$o & $*<0.001$ \\
\hline $105 \mathrm{~min}$ & $1.27 \pm 0.09$ & $1.7 \pm 0.11$ & $2.25 \pm 0.16 \$ 0$ & $*<0.001$ \\
\hline $120 \mathrm{~min}$ & $1.26 \pm 0.12$ & $1.7 \pm 0.12$ & $2.23 \pm 0.18 \$ 0$ & ${ }^{*}<0.001$ \\
\hline $135 \mathrm{~min}$ & $1.24 \pm 0.13$ & $1.7 \pm 0.1$ & $2.28 \pm 0.164 \$ 0$ & $*<0.001$ \\
\hline $150 \mathrm{~min}$ & $1.28 \pm 0.08$ & $1.6 \pm 0.07$ & $2.25 \pm 0.22 \$ 0$ & ${ }^{*}<0.001$ \\
\hline $165 \min$ & $1.28 \pm 0.05$ & $1.65 \pm 0.07$ & $2.3 \pm 0.3 \$ 0$ & ${ }^{*}<0.001$ \\
\hline
\end{tabular}

Data presented as mean $\pm S D$. ${ }^{*}=$ significance between the 3 groups, \# = significance between $D$ and $L$ groups, $\boldsymbol{\$}=$ significance between $L$ and $C$ groups, $\boldsymbol{O}=$ significance between $D$ and $C$ groups.

had a significantly lower MAP compared to the control group at all time points. With respect to the postoperative $\mathrm{HR}$, the dexmedetomidine group had significantly lower values, in immediate postoperative and $2 \mathrm{~h}$ postoperative periods when compared to the control group. The lidocaine group had significantly lower HR at $2 \mathrm{~h}$ postoperative compared to the control group. The dexmedetomidine group had a significantly lower HR immediately postoperatively when compared to the lidocaine group (Figures 2 \& 3). Regarding the end tidal sevoflurane concentration (vol\%), there were statistically significant differences between the three 


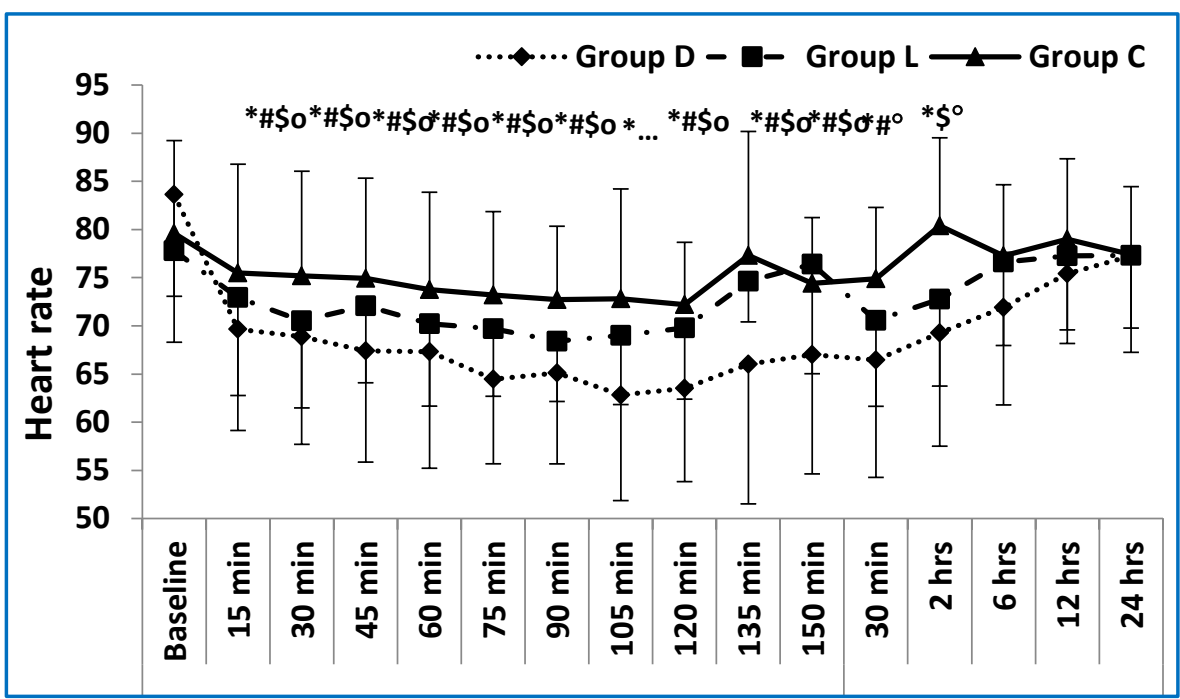

Figure 2: Mean values of heart rate in the three studied groups measured at different time points. (baseline preoperative reading, 15, 30, 45, 60, 75, 90, 105, 120, 135, $150 \mathrm{~min}$ intraoperative and $30 \mathrm{~min}, 2,6,12,24 \mathrm{~h}$ postoperative). $\mathrm{D}$ group = dexmedetomidine group, $\mathrm{L}$ group = lidocaine group, $\mathrm{C}$ group = control group. * = significance between the 3 groups, \# = significance between $D$ and $L$ groups, $\$=$ significance between $\mathrm{L}$ and $\mathrm{C}$ groups, ${ }^{\circ}=$ significance between $\mathrm{D}$ and $\mathrm{C}$ groups.)

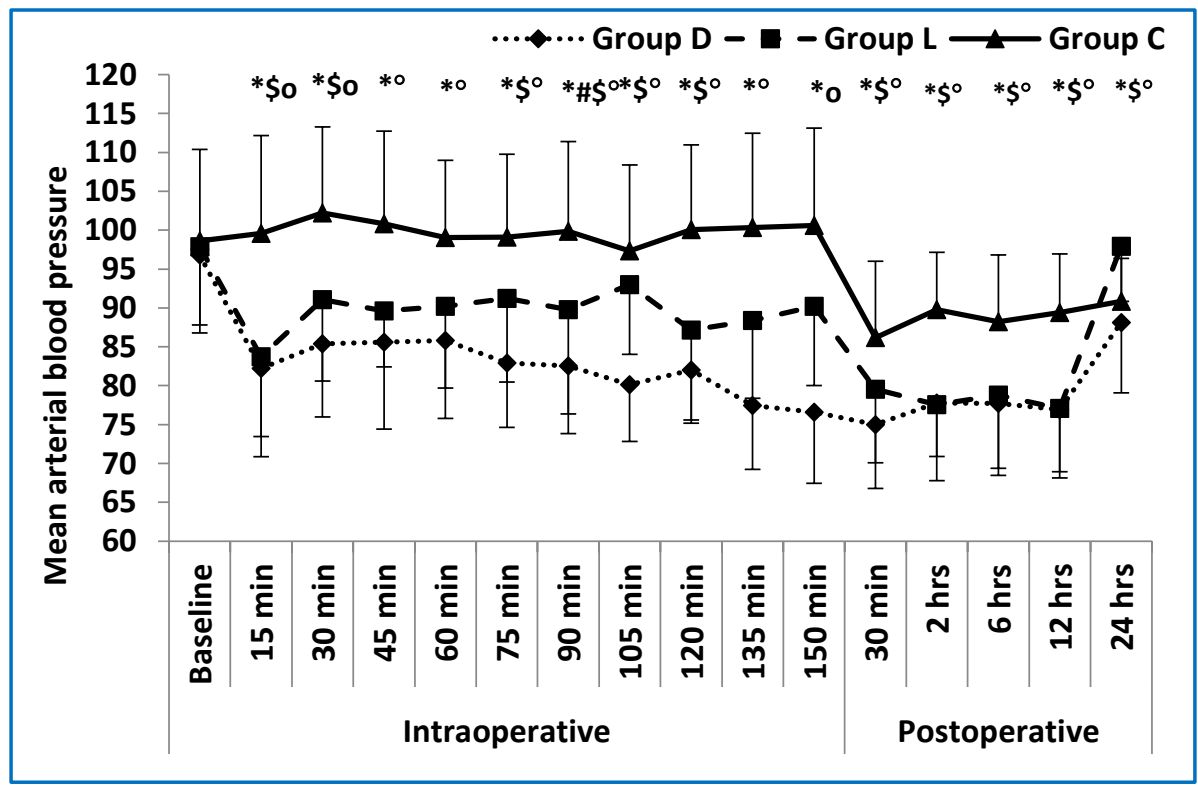

Figure 3: Mean values of MAP in the three studied groups measured at different time points. (baseline preoperative reading, 15, 30, 45, 60, 75, 90, 105, 120, 135, $150 \mathrm{~min}$ intraoperative and $30 \mathrm{~min}, 2,6,12,24 \mathrm{~h}$ postoperative). D group = dexmedetomidine group, L group = lidocaine group, $\mathrm{C}$ group $=$ control group.

* = significance between the 3 groups, \# = significance between $D$ and $L$ groups, $\$=$ significance between $L$ and $C$ groups, ${ }^{\circ}=$ significance between $D$ and $C$ groups.)
VAS was significantly lower in the dexmedetomidine group compared to the control group at all time points $(\mathrm{P}<0.001)$. The lidocaine group had a lower VAS compared to control group and it was statistically significant immediately postoperatively, and at $6 \mathrm{~h}$ and $12 \mathrm{~h}$ postoperative period.

The dexmedetomidine group had lower VAS compared to the lidocaine group but it was only statistically significant at immediately postoperative, $2 \mathrm{~h}$ and $24 \mathrm{~h}$ postoperative measurements (Table 4).

The dexmedetomidine group had a significantly lower morphine consumption and longer time to the first postoperative analgesic requirement, compared to both the lidocaine and the control group. There was no significant difference between the 3 study groups in their recovery time (Table 5).

\section{Discussion}

Tissue injury and surgery initiate a complex process of cytokine cascade as a result of direct stimulation of sympathetic nervous system. The increased production in proinflammatory cytokines leads to metabolic derangement and hemodynamic instability, proportionate to the duration and the severity of the tissue injury. Moreover, the nociceptive and proinflammatory cytokines seem to be directly related to each other; as increased release of proinflammatory groups in all readings $(\mathrm{P}<0.001)$. The dexmedetomidine group had a lower end tidal sevoflurane concentration compared to the lidocaine and the control groups at all time points. The lidocaine group had a lower end tidal sevoflurane concentration compared to the control group (Table 3). cytokines could lead to more severe pain and vice versa. Some released cytokines, such as; tumor necrosis factor alpha (TNFa), and interleukin-6 (IL-6) can change pain signal transmission, through cytokine induced release of some neuroactive substances, e.g., nitric oxide, oxygen 


\begin{tabular}{lllll}
\hline \multicolumn{4}{c}{ Table 4: Postoperative visual analogue scale (VAS) in the 3 studied groups: } \\
& $\begin{array}{l}\text { Group D } \\
(\mathrm{n}=18)\end{array}$ & $\begin{array}{l}\text { Group L } \\
(\mathrm{n}=18)\end{array}$ & $\begin{array}{l}\text { Group C } \\
(\mathrm{n}=18)\end{array}$ & P-value \\
& $0(0-1) \#$ & $3(2-4)$ & $6(4-7) \$ O$ & $<\mathbf{0 . 0 0 1 ^ { * }}$ \\
$\begin{array}{l}\text { Immediately } \\
\text { postoperative }\end{array}$ & & & & \\
$2 \mathrm{~h}$ & $1(0-2) \#$ & $3(2-5)$ & $5(4-6) \mathrm{O}$ & ${ }^{*}<0.001$ \\
$6 \mathrm{~h}$ & $2(2-3)$ & $32-5)$ & $4(3-7) \$ O$ & ${ }^{*}<0.001$ \\
$12 \mathrm{~h}$ & $2(2-4)$ & $3(2-4)$ & $5(4-6) \$ O$ & ${ }^{*}<0.001$ \\
$24 \mathrm{~h}$ & $2(2-4) \#$ & $3(2-4)$ & $5(4-6) \mathrm{O}$ & $<\mathbf{0 . 0 0 1 ^ { * }}$ \\
\hline
\end{tabular}

Data presented as median (interquartile range); * = significance between the 3 groups, \# = significance between $D$ and $L$ groups, $\$=$ significance between $L$ and $C$ groups, $\mathbf{O}=$ significance between $D$ and $C$ groups.

\begin{tabular}{|c|c|c|c|c|}
\hline & $\begin{array}{l}\text { Group D } \\
(n=18)\end{array}$ & $\begin{array}{l}\text { Group L } \\
(n=18)\end{array}$ & $\begin{array}{l}\text { Group C } \\
(n=18)\end{array}$ & P-value \\
\hline Morphine (mg) & $1 \pm 0.5 \#$ & $6.89 \pm 1.23$ & $6.9 \pm 0.80$ & $*<0.001$ \\
\hline Recovery time (min) & $6.67 \pm 0.9$ & $7.11 \pm 0.76$ & $7 \pm 0.84$ & 0.263 \\
\hline $\begin{array}{l}\text { Time to } 1 \text { st rescue } \\
\text { analgesic }(\mathrm{h})\end{array}$ & $6(0-12) \#$ & $2(1.5-6)$ & $2(0-2) 0$ & 0.04 * \\
\hline
\end{tabular}

Data of total morphine consumption and recovery time presented as mean $\pm S D$. Data of time to first request of analgesia presented as median (interquartile range). . * = significance between the 3 groups, \# = significance between $D$ and $L$ groups, $\$=$ significance between $L$ and $C$ groups, $\boldsymbol{O}=$ significance between $D$ and $C$ groups. inflammation, and protect the immune function of surgical patients via combined mechanism of the central and peripheral nervous system alpha adrenergic receptors. 12,13 It inhibits the cytokine production by macrophages and monocytes during the stress response. Additionally, the sympatholytic effect causes stimulation of the cholinergic antiinflammatory pathway and the antinociceptive action, involving interactions between pain and immune factors. 14

Being an alpha-2 adrenoceptor agonist, the dexmedetomidine can inhibit secretion of insulin by stimulating the postsynaptic alpha-2 adrenoceptors of pancreatic beta cells. Moreover, the it attenuates the hypothalamo- free radicals, and excitatory amino acids, resulting in lasting hyperalgesia, fatigue, atrial fibrillation, and cognitive dysfunction as well as a delayed wound healing.10 On the other hand, anti-inflammatory cytokines are also released during inflammation, to counteract these effects, and keep balance besides improving the postoperative outcome. 11

We compared the effect of both dexmedetomidine and lidocaine on two of the proinflammatory cytokines (IL6 and $\mathrm{TNF} \alpha$ ) two stress related release of insulin and lactate, during the first $24 \mathrm{~h}$ postoperative period in patients undergo pelvi-abdominal surgeries (e.g. total abdominal hysterectomy and bilateral salpingooophorectomy with lymph node dissection) showing a remarkable reduced levels in the dexmedetomidine group, compared to the lidocaine and the control group.

Besides the intraoperative end tidal sevoflurane concentration, postoperative VAS and the total $24 \mathrm{~h}$ postoperative morphine consumption were lower in the dexmedetomidine and lidocaine groups compared with the control group. Moreover, these were lower in the dexmedetomidine group compared to the lidocaine group.

Many previous studies demonstrated that dexmedetomidine can attenuate perioperative pituitary-adrenal axis and sympatho-adrenal responses with potential perioperative glucose homeostasis inhibition. 15, 16

The dexmedetomidine inhibits the activity of sympathetic nervous system, and reduces catecholamine and glucocorticoids release, then attenuates the negative impact of the immune function of the surgical cases besides protecting the immune function.17

We demonstrated the efficacy of infusion of lidocaine in reducing the proinflammatory cytokines and surgical stress response compared to the control group. The mechanism by which lidocaine reduces the proinflammatory cytokines could be directly related to its analgesic action in reducing the pressor response, surgically induced sympathetic stimulation, postoperative opioid consumption and pain scores. However, the exact mechanism has not been fully investigated in previously.

The anti-inflammatory effect of lidocaine was demonstrated in colonic surgeries, 8 abdominal hysterectomies, 18 and laparoscopic surgeries.19, $20 \mathrm{~A}$ researcher found decreased levels of IL-6, C-reactive protein and total leucocyte count with an infusion of lidocaine.21 On the other hand, Wuethrich et al. found no significant effect of lidocaine infusion on the surgical 
stress response regarding the cortisol, procalcitonin, and $\mathrm{C}$-reactive protein levels and in relation to the hospital stay, despite using a higher dose than the current study and a higher postoperative infusion dose. However, they didn't measure the plasma level of TNF $\alpha$ and IL-6 as in our study. 22

In our study, the proposed drug regimen included a loading dose before the surgical stimulation, then a maintenance infusion throughout the surgery. Hofer et al. demonstrated that the anti-inflammatory effects of dexmedetomidine can be achieved through pre-emptive administration before the surgical stress stimulation.23

Several studies determined that the use of pre-emptive analgesia, whether as an IV analgesia or as a preoperative regional nerve blocks, decreases the cytokine response, peripheral and central nervous system sensitization, and the pain. 24

\section{Limitations}

The current study has a limitation that the duration of the study was only 24 hours postoperatively, which didn't allow researchers to assess the effect of the study drugs on the postoperative bowel function, the incidence of postoperative ileus and the hospital stay duration. Nonetheless, the effect of lidocaine on the bowl function has previously been investigated. ${ }^{25,26}$

\section{Conclusion}

The intraoperative infusion of either dexmedetomidine or lidocaine, attenuates the postoperative levels of proinflammatory cytokines (IL-6 and TNF $\alpha$ ) and stress related release of serum insulin and lactate). Besides, dexmedetomidine produces lower postoperative pain scores and reduces postoperative opioid consumption compared to, both the lidocaine and the control group, without any hemodynamic consequences to patients who undergone pelvi-abdominal cancer surgeries.

\section{Conflict of interests}

This research was conducted at the National Cancer Institute using available resources.

The authors declare that they have no competing interests.

Ethics approval was obtained from the Institutional Review Board (Approval No.201617050.3). Written informed consent was obtained from the participants before inclusion.

\section{Competing interests}

The authors declare that they have no competing interests.

\section{References}

1. Mokart D, Merlin M, Sannini A, Brun JP, Delpero JR, Houvenaeghel $G$, et al. Procalcitonin, interleukin 6 and systemic inflammatory response syndrome (SIRS): early markers of postoperative sepsis after major surgery. $\mathrm{Br} \mathrm{J}$ Anaesth. 2005;94:767-73. [PubMed] DOI: 10.1093/bja/aei143

2. van Boekel RLM, Warlé MC, Nielen RGC, Vissers KCP, van der Sande R, Bronkhorst EM, et al. Relationship between postoperative pain and overall 30 -day complications in a broad surgical population: an observational study. Ann Surg. 2019;269:856-65. [PubMed] DOI: 10.1097/SLA.0000000000002583

3. Priebe H-J. Pharmacological modification of the perioperative stress response in noncardiac surgery. Best Pract Res Clin Anaesthesiol. 2016;30:171-89. [PubMed] DOI: 10.1016/j.bpa.2016.03.001

4. Li Y, Wang B, Zhang LL, He SF, Hu XW, Wong GT, et al. Dexmedetomidine combined with general anesthesia provides similar intraoperative stress response reduction when compared with a combined general and epidural anesthetic technique. Anesth Analg. 2016;122:1202-10. [PubMed] DOI: 10.1213/ANE.0000000000001165

5. Wang $\mathrm{C}$, Datoo $\mathrm{T}$, Zhao $\mathrm{H}, \mathrm{Wu} \mathrm{L}$, Date A, Jiang $\mathrm{C}$, et al. Midazolam and dexmedetomidine affect neuroglioma and lung carcinoma cell biology in vitro and in vivo. Anesthesiology. 2018;129:1000-14. [PubMed] DOl: 10.1097/ALN.0000000000002401

6. Koppert W, Weigand M, Neumann F, Sittl R, Schuettler J, Schmelz $M$, et al. Perioperative intravenous lidocaine has preventive effects on postoperative pain and morphine consumption after major abdominal surgery. Anesth Analg. 2004:98:1050-5. [PubMed] DOl: 10.1213/01.ANE.0000104582.71710.EE

7. Harvey KP, Adair JD, Isho M, Robinson R. Can intravenous lidocaine decrease postsurgical ileus and shorten hospital stay in elective bowel surgery? A pilot study and literature review. Am J Surg. 2009;198:231-6. [PubMed] DOI: 10.1016/j.amjsurg.2008.10.015

8. Kuo CP, Jao SW, Chen KM, Wong CS, Yeh CC, Sheen MJ, et al. Comparison of the effects of thoracic epidural analgesia and i.v. infusion with lidocaine on cytokine response, postoperative pain and bowel function in patients undergoing colonic surgery. $\mathrm{Br} J$ Anaesth. 2006;97:640-6. [PubMed] DOI: 10.1093/bja/ael217

9. Faul F, Erdfelder E, Lang AG, Buchner A. G*Power 3: a flexible statistical power analysis program for the social, behavioral, and biomedical sciences. Behav Res Methods. 2007;39:17591. [PubMed] DOI: 10.3758/bf03193146

10. Zhang JM, An J. Cytokines, inflammation, and pain. Int Anesthesiol Clin. 2007;45:27-37. [PubMed] DOI: 10.1097/AIA.0b013e318034194e

11. Watkins LR, Milligan ED, Maier SF. Glial proinflammatory cytokines mediate exaggerated pain states: implications for clinical pain. Adv Exp Med Biol. 2003;521:1-21. [PubMed]

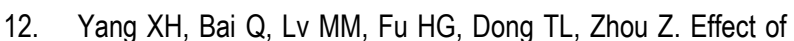
dexmedetomidine on immune function of patients undergoing 
radical mastectomy: a double blind and placebo control study. Eur Rev Med Pharmacol Sci. 2017;21:1112-6. [PubMed]

13. Dong W, Chen MH, Yang YH, Zhang X, Huang MJ, Yang XJ, et al. The effect of dexmedetomidine on expressions of inflammatory factors in patients with radical resection of gastric cancer. Eur Rev Med Pharmacol Sci. 2017;21:3510-5. [PubMed]

14. Ma J, Chen Q, Li J, Zhao H, Mi E, Chen $\mathrm{Y}$, et al. Dexmedetomidine-mediated prevention of renal ischemiareperfusion injury depends in part on cholinergic antiinflammatory mechanisms. Anesth Analg. 2020;130:1054-62. [PubMed] DOI: 10.1213/ANE.0000000000003820

15. Wang XW, Cao JB, Lv BS, Mi WD, Wang ZQ, Zhang C, et al. Effect of perioperative dexmedetomidine on the endocrine modulators of stress response: a meta-analysis. Clin Exp Pharmacol Physiol. 2015;42:828-36. [PubMed] DOI: 10.1111/1440-1681.12431

16. Draghiciu O, Nijman HW, Daemen T. From tumor immunosuppression to eradication: targeting homing and activity of immune effector cells to tumors. Clin Dev Immunol. 2011;2011:439053. [PubMed] DOI: 10.1155/2011/439053

17. Singh S, Singh A. Dexmedetomidine induced catecholamine suppression in pheochromocytoma. J Nat Sci Biol Med. 2014;5:182-3. [PubMed] DOI: 10.4103/0976-9668.127323

18. Yardeni IZ, Beilin B, Mayburd E, Levinson Y, Bessler H. The effect of perioperative intravenous lidocaine on postoperative pain and immune function. Anesth Analg. 2009;109:1464-9. [PubMed] DOI: 10.1213/ANE.0b013e3181bab1bd

19. Wu CT, Borel CO, Lee MS, Yu JC, Liou HS, Yi HD, et al. The interaction effect of perioperative cotreatment with dextromethorphan and intravenous lidocaine on pain relief and recovery of bowel function after laparoscopic cholecystectomy. Anesth Analg. 2005;100:448-53. [PubMed] DOI: 10.1213/01.ANE.0000142551.92340.CC

20. Kaba A, Laurent SR, Detroz BJ, Sessler DI, Durieux ME, Lamy $M L$, et al. Intravenous lidocaine infusion facilitates acute rehabilitation after laparoscopic colectomy. Anesthesiology. 2007;106:11-8. [PubMed] DOI: 10.1097/00000542200701000-00007

21. Sridhar P, Sistla SC, Ali SM, Karthikeyan VS, Badhe AS, Ananthanarayanan $\mathrm{PH}$. Effect of intravenous lignocaine on perioperative stress response and post-surgical ileus in elective open abdominal surgeries: a double-blind randomized controlled trial. ANZ J Surg. 2015;85:425-9. [PubMed] DOI: 10.1111/ans.12783

22. Wuethrich PY, Romero J, Burkhard FC, Curatolo M. No benefit from perioperative intravenous lidocaine in laparoscopic renal surgery: a randomised, placebo-controlled study. Eur J Anaesthesiol. 2012;29:537-43. [PubMed] DOI: 10.1097/EJA.0b013e328356bad6

23. Hofer S, Steppan J, Wagner T, Funke B, Lichtenstern C, Martin $\mathrm{E}$, et al. Central sympatholytics prolong survival in experimental sepsis. Crit Care. 2009;13:R11. [PubMed] DOI: $10.1186 /$ cc7709

24. Bagry $\mathrm{H}$, de la Cuadra Fontaine JC, Asenjo JF, Bracco D, Carli $F$. Effect of a continuous peripheral nerve block on the inflammatory response in knee arthroplasty. Reg Anesth Pain Med. 2008;33:17-23. [PubMed] DOl: 10.1016/j.rapm.2007.06.398

25. Groudine SB, Fisher HA, Kaufman RP, Jr., Patel MK, Wilkins LJ, Mehta SA, et al. Intravenous lidocaine speeds the return of bowel function, decreases postoperative pain, and shortens hospital stay in patients undergoing radical retropubic prostatectomy. Anesth Analg. 1998;86:235-9. [PubMed] DOI: 10.1097/00000539-199802000-00003

26. Bisgaard $\mathrm{T}$, Klarskov $\mathrm{B}$, Kehlet $\mathrm{H}$, Rosenberg J. Preoperative dexamethasone improves surgical outcome after laparoscopic cholecystectomy: a randomized double-blind placebocontrolled trial. Ann Surg. 2003;238:651-60. [PubMed] DOI: 10.1097/01.sla.0000094390.82352.cb 